\title{
Levantamento das autorizações de corte de árvores de Curitiba ${ }^{(1)}$
}

\author{
FRANCINE LORENA CUQUEL ${ }^{(2) ; ~ E R I C A ~ C O S T A ~ M I E L K E ~}{ }^{(3)}$; ROSANA CAMPANHOLO ${ }^{(3)}$
}

\begin{abstract}
RESUMO
A arborização urbana, apesar de ser onerosa para a municipalidade, face aos elevados custos advindos de sua produção e manutenção, melhora a paisagem e a qualidade de vida dos cidadãos. A escolha das espécies mais adequadas para esta finalidade pode contribuir para a redução destes custos pela menor necessidade de corte de árvores adultas. O objetivo deste trabalho foi identificar as principais espécies arbóreas alvo das autorizações de corte em Curitiba, para subsidiar ações futuras que visem à otimização dos recursos financeiros. Para tanto, foram avaliados os pedidos de autorização de corte de árvores, disponíveis no Sistema Informatizado da Secretaria de Meio Ambiente da Prefeitura Municipal de Curitiba, no período de 01/07/2008 a 01/07/2009. Os doze bairros selecionados para análise localizavam-se no entorno de dois quilômetros do centro da cidade. Dos 1.034 pedidos submetidos no referido período, apenas $19,6 \%$ receberam autorização de corte, com destaque para quatro espécies, que responderam por $45,8 \%$ das autorizações de corte emitidas. As principais espécies, cujo corte foi autorizado, foram Alfeneiro (Ligustrum lucidum), em virtude de comprometimento fitossanitário, Acer (Acer negundo) e Extremosa (Lagerstroemia indica), devido à morte do indivíduo, e Ficus (Ficus benjamina), devido a danos causados às edificações.

Palavras-chave: paisagismo, arborização urbana, planejamento urbano, plantas exóticas.
\end{abstract}

ABSTRACT

Survey of the tree cut authorization at Curitiba

\begin{abstract}
The urban forestry, although to be expensive for the Municipality, in face of the high production and maintenance costs, improves the landscape and the citizen's life quality. The choice of the better species for this purpose and their adequate management can contribute for the reduction of the necessity of cut of adult trees. The objective of this work was to identify the main species cut authorization issued at the Curitiba City, Brazil, to subsidize future actions improving the use the financial resources. In such a way, the Curitiba City Hall Environmental Secretary Data System Register for tree cut authorization was analyzed from July 1st 2008 to July 1st 2009. Twelve neighbourhoods downtown area were selected for analysis. From the 1.034 orders submitted in related period, only $19.6 \%$ received cut authorization, with prominence for four species that answers for $45.8 \%$ of the emitted authorizations of cut. The main species authorized were Glossy privet (Ligustrum lucidum), due to pest and disease problems; Maple (Acer negundo), and Crape myrtle (Lagerstroemia indica), due to death, and Ficus (Ficus benjamina), due to damages to buildings.
\end{abstract}

Keywords: landscaping, urban forestry, urban planning, exotic plants.

\section{INTRODUÇÃO}

A arborização urbana é um componente importante da paisagem, que propicia melhoria do microclima, produz sombra, reduz a poluição do ar e a sonora, reduz o impacto causado pelo vento e pela chuva. Além disto, contribui para a beleza da paisagem e qualidade de vida, ajudando o ser humano a mitigar a probabilidade de estresse, conforme citam SILVA et al. (2005).

A produção e manutenção das 300 mil árvores urbanas de Curitiba (CURITIBA, 2009) têm um alto custo para a municipalidade. O custo médio unitário de produção de uma muda arbórea de crescimento rápido (três anos em média) é de $\mathrm{R} \$ 55,69$; de crescimento moderado (quatro anos em média), de R $\$ 71,58$; e de crescimento lento (mais de quatro anos), de R $\$ 88,43$ (LEAL et al., 2008). Entretanto, segundo McPHERSON e SIMPSON (2002) e McPHERSON (2003), os maiores custos de arborização são referentes às operações de poda e remoção de árvores urbanas. Um estudo do valor monetário das árvores urbanas do Município de Maringá (PR) estimou que o valor médio de uma árvore com um ano de idade seja U\$60,00 e com cinquenta anos de idade seja U\$ 6.850,00 (DETZEL et al., 1998). LAERA (2006), num estudo da valoração econômica das árvores de um bairro na cidade do Rio de Janeiro, demonstrou o efeito positivo da presença de árvores na rua sobre o preço dos imóveis. Ainda há de se considerar que muitos municípios brasileiros têm em seu perímetro urbano árvores que, por alguns atributos especiais, são valiosas como patrimônio (ESTELLITA et al., 2007). Isto demonstra a importância da escolha adequada das espécies e de seu manejo, para evitar necessidades futuras de retirada de árvores adultas. Diversas características devem ser avaliadas para a escolha de espécies adequadas para a arborização, tais como espécies sem espinhos no tronco, espécies que não tenham frutos muito grandes, espécies que não apresentem princípio ativo tóxico, de preferência espécies com sistema radicular pivotante e a copa com formato, dimensão e engalhamento adequados (MOZART, 1998, SILVA et al., 2002). Além disto, deve-se considerar a capacidade de adaptação das espécies a fatores bióticos e abióticos constantes no meio urbano.

\footnotetext{
(1) Recebido em 11/01/2010 e aceito para publicação em 30/03/2011.

(2)Professora, Dra. do Departamento de Fitotecnia e Fitossanitarismo da UFPR, Rua dos Funcionários, 1540, Juvevê, CEP 80.035-050, Caixa Postal 19.061, Curitiba, PR, email francine@ufpr.br.

${ }^{(3)}$ Prefeitura Municipal de Curitiba, Av. Manoel Ribas, 2727, CEP 80.010-000, Curitiba, PR, email emielke@smma.curitiba.pr.gov.br, rcampanholo@smma.curitiba.pr.gov.br.
} 
O objetivo desta pesquisa foi identificar as principais espécies da arborização urbana autorizadas para corte pela Prefeitura Municipal de Curitiba (PMC) para subsidiar ações futuras que visem à otimização dos recursos financeiros.

\section{MATERIAL E MÉTODOS}

Esta pesquisa foi desenvolvida em Curitiba, Capital do Estado do Paraná, situada na região Sul do Brasil, latitude $25^{\circ} 25^{\prime} 48^{\prime \prime} \mathrm{S}$ e $49^{\circ} 16^{\prime} 15^{\prime \prime} \mathrm{O}$. A altitude média é de $934 \mathrm{~m}$ acima do nível do mar. O clima da região é classificado, segundo Köeppen, como Cfb, com características de clima subtropical mesotérmico, superúmido, com verões frescos e geadas severas, demasiadamente frequentes (média de cinco geadas/ano), sem estação seca. A temperatura média anual é de $16,5^{\circ} \mathrm{C}$, com média do mês mais quente e mais frio de $24,4^{\circ} \mathrm{C}$ e $12,7^{\circ} \mathrm{C}$, respectivamente. O mês mais chuvoso é janeiro, e o menos é agosto (MAACK, 1968). O município conta com uma área de $432 \mathrm{~km}^{2}$ e 1,6 milhões de habitantes. Ele é composto por 75 bairros, divididos em nove regionais administrativas (Bairro Novo, Boa Vista, Boqueirão, Cajuru, CIC, Matriz, Pinheirinho, Portão e Santa Felicidade). Sua extensão é de $20 \mathrm{~km}$ de Leste a Oeste, e de $35 \mathrm{~km}$ de Norte a Sul (IPPUC, 2009).

A solicitação de autorização de corte de árvores é efetuada diretamente pelo proprietário da área mediante a abertura de um processo na PMC que comprove a posse, quitação dos tributos municipais, objetivo do corte e croquis da área identificando a localização das árvores alvo do processo. Na sequência, um funcionário do Departamento de Meio Ambiente da PMC irá efetuar a vistoria para verificar se a solicitação atende os critérios para emissão da guia de autorização de corte de árvores: risco à segurança pública e problemas fitossanitários. Caso atendido pelo menos um dos critérios, será emitida uma autorização, cujo registro está disponível no Sistema Informatizado da Secretaria de Meio Ambiente da PMC.

Nesta pesquisa, foram avaliadas todas as autorizações emitidas no período de 01/07/2008 a 01/07/2009, em doze bairros selecionados - Alto da XV, Alto da Glória, Água Verde, Batel, Bigorrilho, Bom Retiro, Cristo Rei, Centro Cívico, Mercês, Rebouças, São Francisco e Jardim Botânico - localizados no entorno de dois quilômetros do centro da cidade. Nesta avaliação, foram contabilizados o número de autorizações emitidas por espécie e a justificativa para autorização apresentada pelo funcionário do Departamento de Meio Ambiente que efetuou a vistoria. Considerando a diversidade das espécies autorizadas, optou-se por estudar apenas as espécies cuja representatividade no número total de guias emitidas fosse superior a $1 \%$.

\section{RESULTADOS E DISCUSSÃO}

No período estudado, foram recebidos 1.034 pedidos de autorização de corte de árvores nas vias públicas dos doze bairros selecionados para a pesquisa. Destes pedidos, apenas 203 (19\%) receberam autorização de corte. Isto mostra que a maioria dos pedidos (81\%) não atendia aos critérios para autorização descritos no Código Florestal do Município de Curitiba de risco a segurança pública e problemas fitossanitários. É possível supor que diversas solicitações hajam sido submetidas devido ao requerente considerar a árvore como um elemento indesejável na paisagem, conforme citam SOMMER e SOMMER (1989), seja por causarem transtorno de limpeza das calçadas, entupimento de calhas, bem como sombreamento excessivo.

Neste levantamento, foram identificadas 23 espécies (além das palmeiras), cujas autorizações correspondem a pelo menos 1\% das guias emitidas (Tabela 1). Estas autorizações em conjunto correspondem a $88,50 \%$ das guias emitidas (Tabela 1). Entre as espécies alvo do levantamento, dezesseis são exóticas e sete, nativas. O maior número de espécies exóticas autorizadas para corte pode ser atribuído à maior densidade destas plantas no meio urbano, como já foi apresentado em diversos levantamentos de arborização urbana (ver SILVA et al., 2007; BIONDI e LEAL 2008; BLUM et al., 2008; GOES, 2009; ISERNHAGEN et al., 2009), cujos riscos de se tornarem invasoras em áreas urbanas já foram discutidos por ZILLER (2001) e pelos autores dos levantamentos.

A espécie com maior número de autorizações de corte emitidas foi o Alfeneiro (Ligustrum lucidum), com 16,27\% (Tabela 1). Isto ocorreu principalmente pelo comprometimento fitossanitário, ataque de pragas ou doenças. $\mathrm{O}$ grande número de autorizações pode ser justificado pelo seu comportamento exótico, de crescimento rápido, tanto na sombra quanto a pleno sol, cuja dispersão e crescimento ocorrem de maneira rápida, fazendo-o competir e impedir a regeneração de plantas nativas (INSTITUTO HORUS, 2005) e pela sua alta frequência no município de Curitiba (MILANO, 1984; LEAL, 2007). A predominância de apenas uma espécie ou grupo de espécies pode facilitar a disseminação de pragas e doenças, atualmente muito comuns nas árvores em ambiente urbano (ROCHA et al., 2004), confirmando os dados obtidos nesta pesquisa de pedidos de autorização de corte de Alfeneiro por razões fitossanitárias. Circulando pela cidade, é possível verificar in loco, na região central e nos bairros, de arborização mais antiga, que há cerca de quarenta anos o Alfeneiro era uma das principais espécies selecionadas pela PMC para plantio na rede viária. Em outros levantamentos semelhantes efetuados no Sul do País (MALAVASI e MALAVASI, 2001; SCHUCH, 2006; SILVA et al., 2008), tem sido observada a presença frequente desta mesma espécie. O número de Alfeneiros em áreas urbanas frequentemente ultrapassa o índice recomendado pela INTERNATIONAL SOCIETY OF ARBORICULTURE (2009), de 15\% de frequência para uma espécie em áreas urbanas, conforme foi verificado em Canoas (RS) por CORRÊA (2006), com o Alfeneiro representando $27,5 \%$ do total. Este resultado mostra o desconhecimento da municipalidade no passado sobre as possíveis consequências do plantio indiscriminado desta espécie cujas sementes são disseminadas por pássaros, favorecendo que ela se torne uma espécie invasora, particularmente em áreas degradadas (FERRERAS et al., 2008). Além disto, o pólen de Alfeneiro é alergênico (CARIÑANOS et al., 2002).

Considerando que diversas doenças em plantas arbóreas podem ser favorecidas pela poluição do ar (STACK e LAMEY, 1995) e que o Alfeneiro é uma árvore sensível à poluição do ar, acumulando enxofre em suas folhas em locais com intenso tráfego (CARRERAS et al., 1996), a 
ocorrência de problemas fitossanitários, aliada à homogeneidade de espécies, pode haver sido favorecida pela poluição do ar, consequência do crescimento urbano. Já em 1984, MILANO, em seu estudo sobre a arborização urbana de Curitiba, demonstrava a necessidade de uma seleção de espécies mais adaptadas a um ecossistema com a presença de poluição do ar. Em face do crescimento populacional do Município de Curitiba, nestes 25 anos, de quase 550 mil habitantes (IPPUC, 2009), e da estabilidade econômica, que propiciou o aumento da frota de veículos de passeio do país, é bastante provável que a poluição do ar haja aumentado e que este aumento seja um possível fator de estresse para o Alfeneiro, o qual acaba favorecendo ainda mais a incidência de problemas fitossanitários.

O Acer (Acer negundo) foi a espécie com o segundo maior número de autorizações emitidas, $15,36 \%$ (Tabela 1 ). Isto ocorreu principalmente devido à constatação de morte das plantas. O Acer é uma árvore exótica, nativa da América do Norte, de 10 a 25 metros de altura, frequentemente com diversos troncos, cujas folhas verdes se tornam amareloouro no outono e depois caem no inverno (LORENZI et al., 2003). Sua beleza e resistência à geada incentivaram seu plantio na cidade de Curitiba, tornando-se uma marca da cidade (BIONDI e REISSMANN, 2000). Muito embora a causa da morte das árvores aqui mencionadas não haja sido identificada, um estudo desenvolvido por GILBERTSON e BRADSHAW (1985) mostrou que as principais causas de morte de árvores urbanas são o estresse nutricional e hídrico $(56 \%)$. Uma pesquisa realizada em Curitiba evidenciou, pela análise química foliar, que a rapidez e a intensidade do amarelecimento das folhas nesta espécie variavam de acordo com o local e as condições da árvore, e que este era um mecanismo de adaptação ao estresse imposto às árvores no meio urbano desfavorável (BIONDI e REISSMANN, 2000). Os dados obtidos nesta pesquisa concordam com BIONDI e REISSMANN (2000), sugerindo que a morte do Acer, observada in loco, haja sido devida ao estresse imposto às árvores no meio urbano desfavorável. Entre as 24 espécies avaliadas na arborização de ruas de Baltimore (USA), o Acer negundo foi uma das que apresentaram maior porcentagem de mortalidade, ocupando o quarto lugar nesse quesito (NOWAK et al., 2004), mostrando que não apenas no Brasil, mas em outros locais ela também é uma espécie vulnerável ao ecossistema urbano.

A terceira espécie mais autorizada foi a Extremosa (ou Resedá) (Lagerstroemia indica), com 9,34\% das autorizações de corte, principalmente devido à morte das plantas (Tabela 1). A Extremosa é uma árvore exótica de pequeno porte, folhas semicaducas, copa de forma arredondada, cujo plantio é recomendado para pequenos espaços, inclusive, seu plantio é permitido sob a rede de energia elétrica (COPEL, 2009). Sua morte pode ser atribuída ao ataque por míldio, mancha foliar, mancha negra e podridão da raiz (BIONDI e ALTHAUS, 2005).

Considerando que os fatores que levam à morte das árvores nos grandes centros urbanos frequentemente podem estar associados e ocorrer simultaneamente (GILBERTSON e BRADSHAW, 1985), um possível agravante para as espécies anteriormente citadas é a alta infestação por erva-de-passarinho, uma planta hemiparasita de galhos e troncos de árvores e arbustos (EMBRAPA, 2004), que em ataque avançado leva à morte a planta hospedeira. LEAL et al. (2006) constataram em Curitiba a presença de ervade-passarinho em 28,19\% das árvores avaliadas. Coincidentemente, a maior incidência de erva-de-passarinho, observada por LEAL et al. (2006), foi nas três árvores com maior número de autorizações de corte em Curitiba: Ligustrum lucidum, Lagerstroemia indica e Acer negundo. O baixo grau de infestação por erva-de-passarinho presente na maioria das árvores amostradas de Curitiba por LEAL et al. (2006) levou estes autores a indicar que ainda há possibilidade de controle desses hemiparasitas, sem maior comprometimento das árvores, utilizando como medidas de controle a poda ou a retirada manual, de acordo com a forma diferenciada de ocupação da copa. Cabe à municipalidade prover ações eficientes de controle para evitar a necessidade futura de corte das árvores. Se forem consideradas as estatísticas citadas por LEAL et al. (2006), de $28,19 \%$ das árvores do município infestadas por erva-depassarinho, e considerando as estatísticas de que Curitiba apresenta trinta mil árvores na rede viária (CURITIBA, 2009), seria de se estimar a necessidade de poda ou retirada manual de erva-de-passarinho de cerca de dez mil árvores. Considerando a inexistência de produto químico registrado no mercado nacional para controle da erva-de-passarinho e as dificuldades pertinentes à aplicação desses produtos no meio urbano, certamente é melhor atender às recomendações de SEITZ (2009). Ele considera que o desrespeito às exigências edáficas das árvores (solos compactados, pobres em matéria orgânica, sem a fauna apropriada) não permite o desenvolvimento de árvores sadias, propiciando a formação de árvores com folhagem rala, propensas ao ataque de insetos e de erva-de-passarinho e que, embora possam ser executadas ações para eliminar a erva-de-passarinho, a correção do solo, no tocante à sua biologia e aeração, é a medida de efeito mais duradouro.

A quarta espécie mais autorizada foi o Ficus (Ficus benjamina), com 4,82\%, das autorizações de corte (Tabela 1), principalmente devido ao seu sistema radicular vigoroso causar danos às edificações. Apesar de haver recomendações da INTERNATIONAL SOCIETY OF ARBORICULTURE (2009), baseadas em estudos científicos, para o correto plantio de árvores em ambiente urbano, na maioria dos casos são os moradores que escolhem as espécies que ficarão em frente a seus imóveis (CORRÊA, 2006). Cabe ressaltar que, embora a PMC não produza Ficus para arborização urbana, o plantio de Ficus é frequentemente efetuado como cerca viva pelo morador, por considerá-la vistosa. Certamente esse indivíduo desconhece o comportamento agressivo desta espécie arbórea em pequenos espaços, o qual, aliado à falta de manutenção, frequentemente ocasiona danos às calçadas, às redes aéreas de luz e telefonia (VEIGA et al., 1999; ROCHA et al., 2004; SILVA et al., 2008). A PMC, sabendo dos problemas de plantio de espécies exóticas no meio urbano, vem desenvolvendo, desde 2007, o Programa Biocidade, cujas ações, entre outras, envolvem a erradicação das árvores exóticas invasoras das Unidades de Conservação de Curitiba e também o incentivo à população, através de campanhas de conscientização, para que conheça as vantagens e plante as espécies ornamentais nativas no ambiente urbano.

A interferência da população local na arborização pôde 
ser verificada pela frequência de espécies frutíferas - Nespereira (Eriobotrya japonica), Abacateiro (Persea americana), Amoreira (Morus nigra) e Goiabeira (Psidium guajava) - nas autorizações emitidas, cuja presença na arborização urbana já foi verificada anteriormente (ROSSATTO et al., 2008).

\section{CONCLUSÕES}

1. A maioria das solicitações de corte de árvores urbanas não é autorizada;

2. A maioria das autorizações emitidas é para árvores exóticas;

3. As quatro principais espécies autorizadas para corte na rede viária são Alfeneiro (Ligustrum lucidum), Acer (Acer negundo), Extremosa (Lagerstroemia indica) e Ficus (Ficus benjamina); e

4. As principais causas de autorização de corte destas quatro espécies são o comprometimento fitossanitário, a morte e o fato de ocasionarem danos às edificações.

\section{REFERÊNCIAS}

BIONDI, D.; ALTHAUS, M. Árvores de rua de Curitiba: cultivo e manejo. Curitiba: FUPEF, 2005. 177p.

BIONDI, D.; LEAL, L. Caracterização das plantas produzidas no Horto Municipal da Barreirinha - Curitiba/PR. Revista da Sociedade Brasileira de Arborização Urbana, Piracicaba, v.3, n.2, p.20-36, jun. 2008.

BIONDI, D.; REISSMANN, C. B. Estratégia de Acer negundo em relação ao estresse urbano. 2000. Disponível em: http://www.floresta.ufpr.br/ paisagem/laboratorio02.htm. Acesso em: 31 out. 2009.

BLUM, C. T.; BORGO, M.; SAMPAIO, A. C. F. Espécies exóticas invasoras na arborização de vias públicas de Maringá-PR. Revista da Sociedade Brasileira de Arborização Urbana, Piracicaba - SP, v.3, n.2, p.78-97, 2008.

CARIÑANOS, P.; ALCÁZAR, P.; GALÁN, C.; DOMINGUEZ, E. Privet pollen (Ligustrum sp.) as potential cause of pollinosis in the city of Córdoba, south-west Spain. Allergy, Montpellier, v.57, p.92-97, 2002.

CARRERAS, H. A.; CAÑAS, M. S.; PIGNATA, M. L. Differences in responses to urban air pollutants by Ligustrum lucidum Ait. and Ligustrum lucidum Ait. f. tricolor (Rehd.) Rehd. Environmental Pollution, Kidlington, v.93, n.2, p.211-8, 1996.

COPEL. Características importantes para uma boa integração das árvores com o meio ambiente urbano. Disponível em: http://www.copel.com/. Acesso em: 30 out. 2009.

CORRÊA, L. da R. Relação entre o critério socioeconômico e parâmetros ecológicos relativos à arborização viária de Canoas, Brasil. Pesquisas, Botânica, São Leopoldo, n.57, p.303-318, 2006.

CURITIBA. Disponível em: www.curitiba.pr.gov.br.
Acesso em: 23 out. 2009.

DETZEL, V. A.; MILANO, M. S.; Hoeflich, V.; Firkowski, C. Desenvolvimento de um método de avaliação monetária. Floresta, Curitiba, v.28, n. 1/2, p.31-49, 1998.

EMBRAPA. Comunicado Técnico, n. 115. Disponível em: http:/www.cnpf.embrapa.br/publica/comuntec/edicoes/ com_tec115.pdf. Acesso em: 28 out. 2004.

ESTELlitA, M.; DEMATTÊ, M. E. S. P. Índice de Valor Paisagístico para árvores em ambiente urbano. Revista Brasileira de Horticultura Ornamental, Campinas, v.12, n.2, p.103-111, 2007.

FERRERAS, A. E.; TORRES, C.; GALETTO, L. Fruit removal of an invasive exotic species (Ligustrum lucidum) in a fragmented landscape. Journal of Arid Environments, Kidlington, v.72, n.9, p.1573-1580, 2008.

GILBERTSON, P.; BRADSHAW A. D. Tree survival in cities: the extent and nature of the problem. Arboricultural Journal, Champaign, v.9, p.131-42, 1985.

GOES, G.S. Arborização de ruas e praças em Salvador, BA: à luz da Ecologia e Permacultura. Salvador: Universidade Federal da Bahia, 2009. Dissertação (Mestrado em Ciências Biológicas).

INSTITUTO HÓRUS DE DESENVOLVIMENTO E CONSERVAÇÃO AMBIENTAL / THE NATURE CONSERVANCY. Ligustrum lucidum. 2005. Disponível em: www.institutohorus.org.br/download/fichas/Ligustrum_lucidum.htm. Acesso em: 25 out. 2009.

INTERNATIONAL SOCIETY OF ARBORICULTURE. Disponível em: http://www.isa-arbor.com. Acesso em: 25 out. 2009.

IPPUC. Curitiba em Dados. Disponível em: www.ippucnet.ippuc.org.br. Acesso em: 24 out. 2009.

ISERNHAGEN, I.; BOURLEGAT, J. M. G.; CARBONI, M. Trazendo a riqueza arbórea regional para dentro das cidades: possibilidades, limitações e benefícios. Revista da Sociedade Brasileira de Arborização Urbana, Piracicaba, v.4, n.2, p.117-138, 2009.

LAERA, L. H. N. Valoração econômica da arborização: a valoração dos serviços ambientais para a eficiência e manutenção do recurso ambiental urbano. Niterói: Universidade Federal Fluminense, 2006. 131p. Dissertação (Mestrado em Ciência Ambiental).

LEAL, L. Custos das árvores de rua - estudo de caso: cidade de Curitiba / PR. Curitiba: Universidade Federal do Paraná, 2007. Dissertação (Mestrado em Ciências Florestais).

LEAL, L.; BIONDI, D.; ROCHADELLI, R. Custos de implantação e manutenção da arborização de ruas da cida- 
de de Curitiba, PR. Árvore, Viçosa, v.32, n.3, p.557-565, 2008 .

LEAL, L.; BUJOKAS, W. M.; BIONDI, D. Análise da infestação de erva-de-passarinho na arborização de ruas de Curitiba, PR. Floresta, Curitiba, v.36, n.3, p.323-330, 2006

LORENZI, H.; SOUZA, H. M.; TORRES, M. A. V.; BACHER, L. B. Árvores Exóticas no Brasil: madeireiras, ornamentais e aromáticas. Nova Odessa: Plantarum, 2003. $173 \mathrm{p}$.

MAACK, R. Geografia do Estado do Paraná. Curitiba: BADEP/ UFPR/ IBPT, 1968. 350p.

MALAVASI, U. C.; MALAVASI, M. DE M. Avaliação da arborização urbana pelos residentes - estudo de caso em Mal. Cândido Rondon, Paraná. Ciência Florestal, Santa Maria, v.11, n.1, p.189-193, 2001.

McPHERSON, E. G. A benefit-cost analysis of ten street tree species in Modesto, California, U. S. Journal of Arboriculture, California, v.29, n.1, p.1-7, 2003.

McPHERSON, E. G.; SIMPSON, G. R. A comparison of municipal forest benefits and costs in Modesto and Santa Monica. Urban Forestry and Urban Greening, California, v.1, p.61-74, 2002.

MILANO, M.S. Avaliação e análise da arborização de ruas de Curitiba, PR. Curitiba: Universidade Federal do Paraná, 1984. 130 p. Dissertação (Mestrado em Engenharia Florestal).

MOZART, P.S. Verdes Urbanos e rurais: orientação para arborização de cidades e sítios campesinos. Porto Alegre: Cinco Continentes, 1998. 242 p.

NOWAK, D. J.; KURODA, M.; CRANE, D. E. Tree mortality rates and tree population projections in Baltimore, Maryland, USA. Urban Forestry and Urban Greening, California, v.2, p. 139-147, 2004.

ROCHA, R. T.; LELES, da P. S. S., OLIVEIRA, S. N. Arborização de vias públicas em Nova Iguaçu, RJ: o caso dos bairros Rancho Novo e Centro. Revista Árvore, Viçosa, v.28, n.4, p.599-607, 2004.

ROSSATTO, D. R.; TSUBOY, M. S. F.; FREI, F. Arborização Urbana na Cidade de Assis-SP: Uma Abordagem Quantitativa. Revista da Sociedade Brasileira de Arborização Urbana, Piracicaba, v.3, n.3, p. 1-16, set. 2008.
SCHUCH, M.I.S. Arborização urbana: uma contribuição à qualidade de vida com uso de geotecnologias. Santa Maria: Universidade Federal de Santa Maria, 2006. Dissertação (Mestrado em Geomática).

SEITZ, R. A. Vegetação no meio urbano: manejo e recuperação. Disponível em: http://www.sobrade.com.br/ eventos/2005/visinrad/palestras/rudi_arno_seitz_revegetacao_meio_urbano.pdf. Acesso em: $3 \overline{0}$ out. 2009.

SILVA, E. M.; SILVA, A. M.; MELO, P. H.; BORGES, S. S.; LIMA, S. C. Estudo da arborização urbana do bairro Mansour, na cidade de Uberlândia-MG, Revista Caminhos de Geografia, v.3, n. 5, p.73-83, 2002.

SILVA, L. F. DA, BERTONI, J. E. A.; MOLINI, A. M.; MATTHES, L, A. F. Arborização viária urbana: espécies de pequeno porte com potencial de uso. Revista Brasileira de Horticultura Ornamental, Campinas, v.11, n.1, p.1320, 2005.

SILVA, L. M.; HASSE, I.; MOCCELIN, R.; ZBORALSKI, A. R. Arborização de vias públicas e a utilização de espécies exóticas: o caso do bairro Centro de Pato Branco/PR. Scientia Agraria, Curitiba, v.8, n.1, p.47- 53, 2007.

SILVA, L. F. da; VOLPE-FILIK, A.; LIMA, A. M. L. P.; SILVA-FILHO, D. F. Análise da arborização viária em dois bairros de Americana (SP). Revista Brasileira de Horticultura Ornamental, Campinas, v.14, n.2, p.147-158, 2008.

SOMMER, R.; SOMMER, B.A. The factor structure of street tree attributes. Journal of Arboriculture, California, v.15, p.243-245, 1989.

STACK, R. W.; LAMEY, H. A. Deciduous Tree Diseases. North Dakota State: University Extension Service Manual, 1995. $12 \mathrm{p}$.

VEIGA, B. G. A.; COUTINHO, C. L.; MALAVASI, U. C. Planejamento, manejo e aspectos sociais em arborização urbana: o caso do bairro ecologia, Seropédica, RJ. Floresta e Ambiente, Rio de Janeiro, v.6, n.1, p.144-146, jan./dez. 1999.

ZILLER, S. R. Plantas exóticas invasoras: a ameaça da contaminação biológica. Ciência Hoje, Campinas, v.30, n.178, p.77-79, 2001. 
Tabela 1. Autorizações de corte de árvores emitidas para pedidos provenientes de doze bairros do Município de Curitiba (PR) no período de 01/07/2008 a 01/07/2009. ( $\mathrm{E}=$ espécie exótica, $\mathrm{N}=$ espécie nativa).

\begin{tabular}{|c|c|c|c|c|}
\hline & Nome científico & Nome vulgar & Família & Origem \\
\hline 1 & Ligustrum lucidum & Alfeneiro & Oleaceae & Exótica \\
\hline 2 & Acer negundo & Acer & Aceraceae & Exótica \\
\hline 3 & Lagerstroemia indica & Extremosa & Lythraceae & Exótica \\
\hline 4 & Ficus benjamina & Ficus & Moraceae & Exótica \\
\hline 5 & Eriobotrya japonica & Nespereira & Rosaceae & Exótica \\
\hline 6 & Eucalyptus sp & Eucalipto & Myrtaceae & Exótica \\
\hline 7 & Palmeiras & Palmeiras & & \\
\hline 8 & Araucaria angustifolia & Araucária & Arancariaceae & Nativa \\
\hline 9 & Melia azedarach & Cinamomo & Meliaceae & Exótica \\
\hline 10 & Pittosporum undulatum & Pau-incenso & Pittosporaceae & Exótica \\
\hline 11 & Persea americana & Abacateiro & Lauraceae & Exótica \\
\hline 12 & Morus nigra & Amoreira & Moraceae & Exótica \\
\hline 13 & Schinus terebinthifolius & Aroeira-vermelha & Anacardiaceae & Nativa \\
\hline 14 & Tipuana tipu & Tipuana & Fabaceae & Exótica \\
\hline 15 & Psidium guajava & Goiabeira & Myrtaceae & Exótica \\
\hline 16 & Anadenanthera colubrina & Monjoleiro & Fabaceae & Nativa \\
\hline 17 & Olea europaea & Oliveira & Oleaceae & Exótica \\
\hline 18 & Hovenia dulcis & Uva-do-Japão & Rhamnaceae & Exótica \\
\hline 19 & Tabebuia chrysotricha & Ipê-amarelo & Bignoniaceae & Nativa \\
\hline 20 & Jacaranda mimosifolia & Jacarandá & Bignoniaceae & Exótica \\
\hline 21 & Koelreuteria paniculata & Lanterna-japonesa & Sapindaceae & Exótica \\
\hline 22 & Chorisia speciosa & Paineira & Bombacaceae & Nativa \\
\hline 23 & Psidium cattleyanum & Araçá-vermelho & Myrtaceae & Nativa \\
\hline \multirow[t]{3}{*}{24} & Tibouchina granulosa & Quaresmeira & Melastomataceae & Nativa \\
\hline & Outras (incidência por espécie $\leq 1 \%$ ) & & & \\
\hline & Total & & & \\
\hline
\end{tabular}

